\title{
COMF 891007-14
}

UCRL- 101241

PREPRINT

\section{PRORRAM CICC FLOM! AND HEAT TRANSFER IN CABIE-IN-CONDUTT CONDUCTORS}

Pobert L. Wrong

This paper was prepared for submittal to

13th Symposium on Fusion Engineering

Knoxville, IN

October 2 - 6, 1989

November 20, 1989

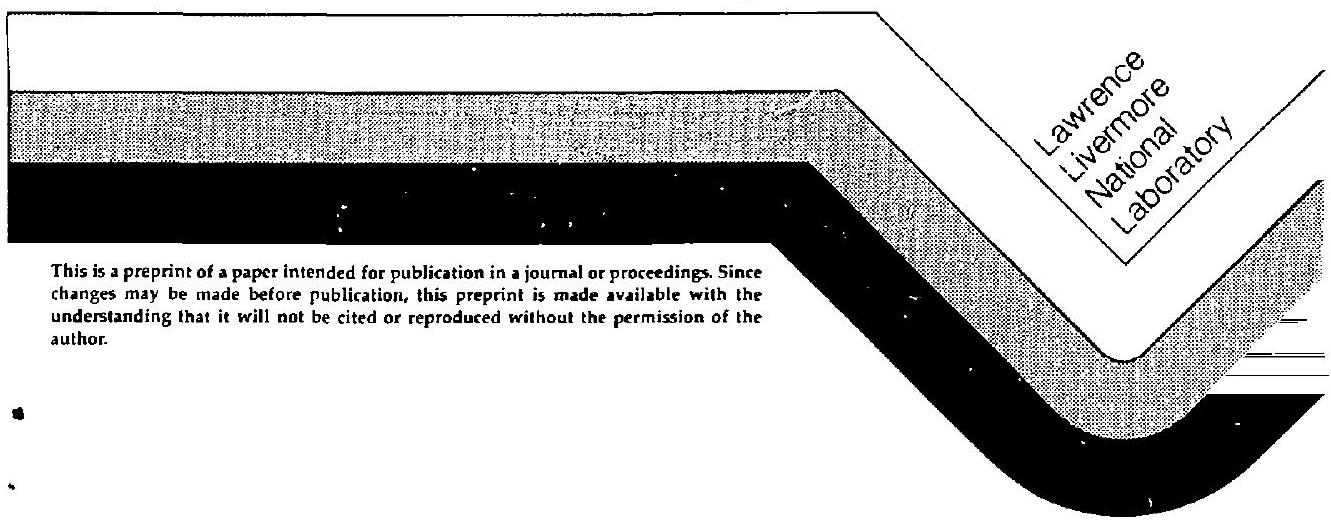




\section{DISCLAJMER}

Thb docuned wes prepared an acceunt of work spowared by an epswcy of the United Suten Goverament. Neilher the United Stntes Goverancal wor the Undveraity

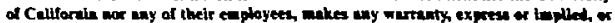

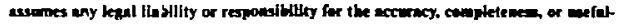
ness of any information, apparatson produch, or prosess dlectened, or represents that

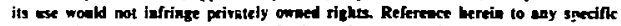

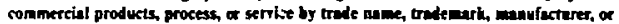

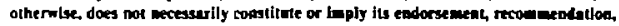

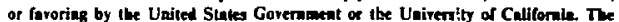
riews acd opinioms of muthors expressed herein do sot aectisarly state oc reflect those of the Uniled States Govern ment or the University of Californin, and shall ont

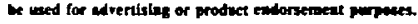




\author{
Roberl L. Wong \\ Lawrence Livermore National Laboratory \\ University of California \\ P.O. Box 5511, I-643 \\ Livermore, CA 94550
}

UCRL-- 101241

DE90 901519

\section{Abstrack}

Computer program CICC has been written for use in the thermo-fluids design of superconducting magnets for tokamak reactors, which use forced-flow, helium-cooled, cable-in-conduir conductors (CICC). In addition to background heat loads that vary with space and time, these superconductors can develop normal zones that generate electrical resistance heat. Program CICC models the transient thermodynamic and fluid-dynamic system response to background heating and normal-zone propagation in the superconductor. The computational algorithm described in this paper couples a onedimensional, compressible pipe-flow model (including flow choking) with two-dimensional, axisymmetric heatconduction models of the superconductor cable, the conduit, and the epoxy-conduit insulation. National Institute of Standards and Technology helium properties are used. The model is verified by comparison with mersured temperature and pressure profiles from thermal expulsion experiments.

\section{Introduction}

One of the candidate conductor designs for superconducting magnets proposed for future tokamak reactors utilize magnets with forced-flow, helium-cooled cable-in-conduit condurtors (CICC). The electrical heat generated when this conductor becomes normal is transferred to the helium coolant, causing the helium to heat rapidly. This causes high helium pressures inside the conductor, forcing the helium to flow in both directions away from the heated zone.

\section{Program CiCC}

Program CICC simulates the helium-fluid-dynamic response as a transient one dimensional, compressible flow. This flow model is combined with axisymmetric CICC conductor and insulation models (Fig. 1) and the equation of staie for helium. [4].

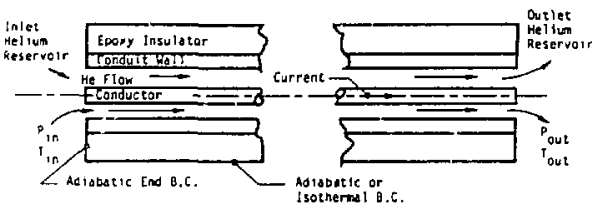

Figure 1. Forced-flow-cooled conductor schematic.

The helium flow is described by three onedimensional pipe-flow-conservation equations:

1. Helium momentum equation:

$$
\frac{\partial(\rho u)}{\partial t}=-\frac{\partial}{\partial x}\left(p+\rho u^{2}\right)-\left(\frac{f}{d_{h}}\right)\left(\frac{1}{2} \rho u|u|\right)
$$

The experimental friction-factor correlation from Lue, et al. $[1,2]$ is used.

2. Helium continuity equation:

$$
\frac{\partial p}{\partial t}=-\frac{\partial(\rho u)}{\partial x}
$$

3. Helium energy equation:

$$
\begin{aligned}
& \left(\frac{\partial}{\partial t}\right)\left[\rho\left(\mathrm{e}+\frac{1}{2} \mathrm{u}^{2}\right)\right]=-\frac{\partial}{(\partial x)}\left[(\rho \mathrm{u})\left(\mathrm{h}+\frac{1}{2} \mathrm{u}^{2}\right)\right] \\
& +\left(\frac{\partial}{\partial x}\right)\left(\mathrm{k} \frac{\partial T}{\partial x}\right)+\frac{l}{A_{\mathrm{c}}}\left[\frac{A_{t c}}{R_{c}}\left(T_{c}-T\right)+\frac{A_{t w}}{R_{w}}\left(T_{w}-T\right)\right]
\end{aligned}
$$

The experimental, convective, heat-transfer correlation from Giarratano [3] is used.

All of the other CICC conductor components are solid. They are each described by an axisymmetric energy equation:

1. Conductor energy equation:

$$
\left(\rho_{c} C_{c}\right)\left(\frac{\partial T_{C}}{\partial x}\right)=\frac{\partial}{\partial x}\left(\mathrm{ECu}_{u} \mathrm{kCu} \frac{\partial T_{c}}{\partial x}\right)+\frac{1}{A_{G C}}\left[\frac{A_{t c}}{R_{c}}\left(T-T_{C}\right)\right]+\left(Q_{g e n}\right)
$$

2. Conduit-wall energy equation:

$$
\begin{aligned}
& \left(\rho_{w} C_{w}\right)\left\{\left(\frac{\partial T_{w}}{\partial t}\right)=\frac{\partial}{\partial x}\left(k_{w} \frac{\partial T_{w}}{\partial x}\right)\right. \\
& +\frac{1}{A_{c w}}\left\{\frac{A_{t w}}{R}\left(T-T_{w}\right)+\frac{\left(A_{t e}\right)_{1}}{\left(R_{e}\right)_{1}}\left[\left(T_{e}\right)_{1}-T_{w}\right)\right\}
\end{aligned}
$$

3. Epoxy-insulation energy equation for layer n:

$$
\begin{aligned}
& \left(\rho_{e} C_{e}\right)\left[\frac{\partial\left(T_{e}\right)_{n}}{\partial t}\right]=\frac{\partial}{\partial x}\left\{k_{e}\left(\frac{\partial\left(T_{e}\right)_{n}}{\partial x}\right)\right\} \\
& \left.+\frac{1}{\left(A_{c e}\right)_{n}}\left\{\frac{\left(A_{t e}\right)_{n}}{\left(R_{e}\right)_{n}}\left[\left(T_{e}\right)_{n-1}-\left(T_{e}\right)_{n}\right]+\frac{\left(A_{t e}\right)_{n+1}}{\left(R_{e}\right)_{n+1}} \mid\left(T_{e}\right)_{n+1}-\left(T_{t}\right)_{n}\right]\right\}
\end{aligned}
$$

The epoxy insulation is not a good conductor, so allowances are made for dividing the insulation thickness into multiple circumferertial layers.

Equations 1 though 6 and the equation of state [4] are solved simultaneously by the method of lines. The spatial derivatives are approximated by the staggered-grid, finite 
differencing scheme shown in Fig. 2 [5]. The conservation elements for the continuity and energy equations are staggered relative to the elements for the momentum equation. This stabilizes the calculation for the pressure in the momentum equation. The resulting system of transient ordinary differential equations is then solved using DASSL 16].
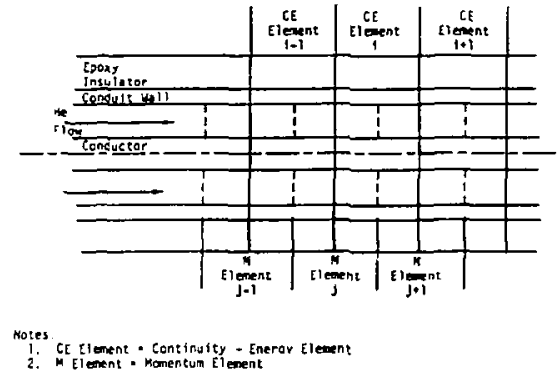

Figure 2. Staggered grid in section of conductor.

\section{Experimental Verification}

Program CICC was verified by comparison with the results of thermal expulsion experiments of Lue and Miller, et.al. $[7,8]$. Their experiments simulated a CICC conductor quenching over the entire length by constructing a conductor using copper wire in a conduit. The conductor is wound around a 10-mm-thick, PVC-pipe mandrel and placed inside a liquid-helium-cooled, cylindrical, stainless-steel dewar. There is about $1 \mathrm{~mm}$ of insulation between the coil turns and $4 \mathrm{~mm}$ of insulation between the coils and the dewar wall [7]. The CICC conductor was initially filled with stagnant helium. Current was then passed through the copper wire, heating it along the entire conductor length and expelling helium out of the open conductor ends. The experiments with the 69-m-long conductor were made with one end closed and with both ends open. In order to match the experimental boundary conditions using program CICC, the experimental geometry with one end of the 69-m-long conductor closed had to be modelled as a 138-m-long conductor with both ends open. The insulation is assumed to be $2-\mathrm{mm}$ thick.

Figures 3-5 compare the calculated and experimental transient pressures at the middle of the conductor model for the gesmetry with one end closed $(L=138 \mathrm{~m})$. Figures $6-8$ compare the pressures at the middle of the conductor model for the geometry with both ends open ( $\mathrm{L}$ $=69 \mathrm{~m}$ ). The currents range from $760 \mathrm{~A}$ to $1540 \mathrm{~A}$ and have a square-wave-pulse shape that is on for the entire 7 seconds.

Figure 9 compares the calculated and experimental transient temperatures at the middle of the conductor for a case with both ends open and a current of $940 \mathrm{~A}$.

The computed results agree with the measured values, considering the limitations of the axisymmetric heat-transfer model and the uncertainty in the values of the turbulent friction factor. The pressure represents the

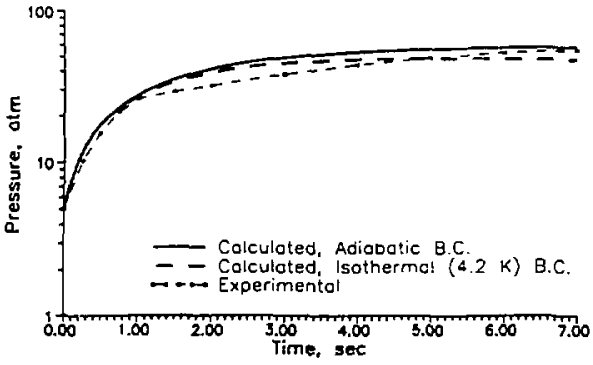

Figure 3. Thermal Expulsion, 138-m, 760-A conductor middle He pressure.

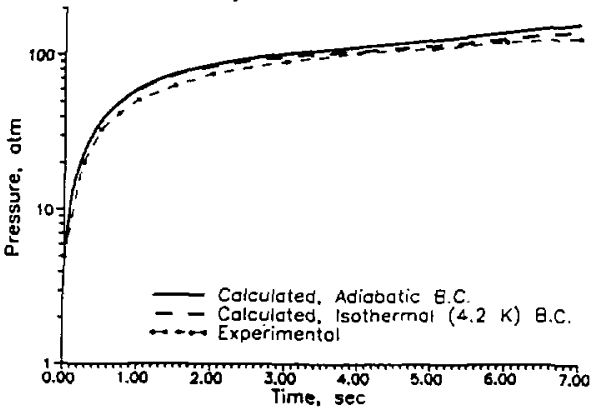

Figure 4. Thermal Expulsion, 138-m, 1250-A conductor middle He pressure.

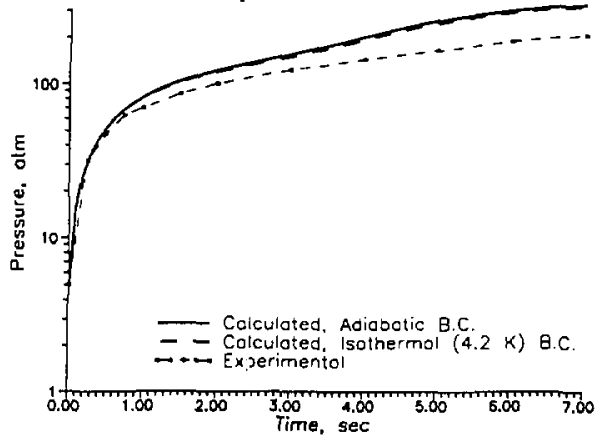

Figure 5. Thermal Expulsion, 138-m, 1540-A conductor middle He pressure.

results of a delicate balance between the radjal heat loss out of the conductor and the friction pressure drop. The calculated pressures are higher than the experimental pressures for the runs with one end closed. The calculations are lower than the experimental pressures for the runs with both ends open. This indicates that the friction factor is low and that an additional unaccounted for heat conduction path exists between the two bifilerwound conductor legs when one end is clused 


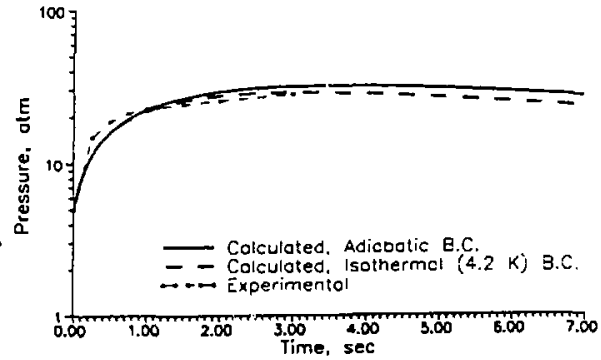

Figure 6. Thermal Expulsion, 69-m, 760-A conductor middle He pressure.

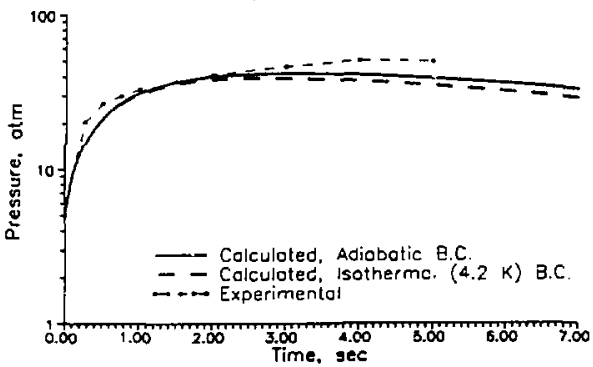

Figure 7. Thermal Exp : :ion, 69-m, 940-A conductor middle He pressure.

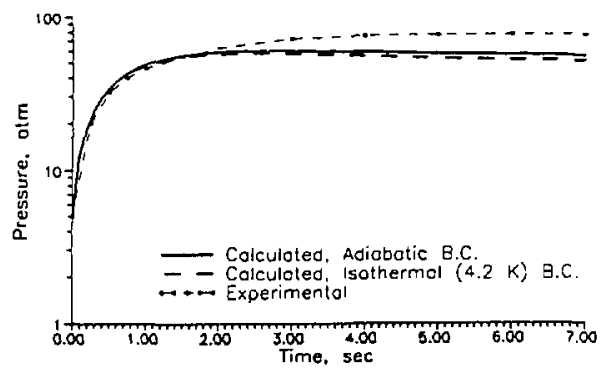

Figure 8. Thermal Expulsion, 69-m, 1250-A conductor middle He pressure.

\section{Conciusion}

Program CICC has been written to solve the

- transient thermal-fluids problem of a forced-flow, heliumcooled CICC conductor going normal. The program can be used to determine the stability of a conductor to a given heating situation, or to determine the survivability of a conductor to a given quench situation. For further informaticn about program CICC, see Refs. [9] and [10].

\section{Acknowledgments}

This work was performed under the auspices of the U.S. Cefartment of Energy by the Lawrence Livermore Nationsi Laboratory under Contract W-7405-Eng-48.

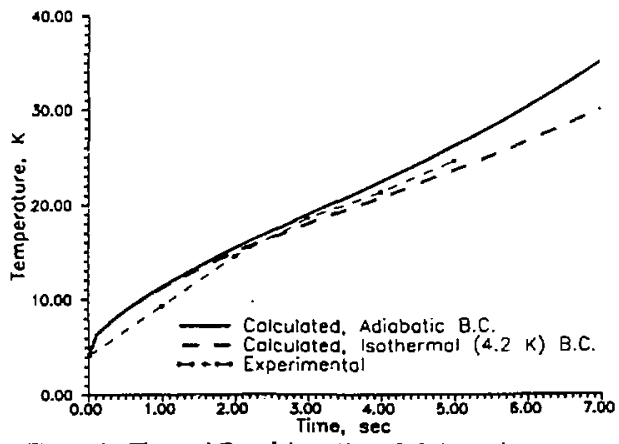

Figure 9. Thermal Expulsion, 69-m, 940-A conductor middle temperature.

\section{References}

[1] J.W. Lue, J.R Miller, and J.C. Lottin, "Pressure Drop Measurement on Forced Flow Cable Conductors," IEEE Transactions of Magnetics, vol. mag-15, no. 1 , pp. 53-55, Jan. 1979.

(2) R.J. Hooper, "Friction Facior Correlations for Cable-InConduit Conductors," FEDC-M-84-E/M-016, Fusion Engineering Design Center, Oak Ridge National Laboratory, March 5, 1984.

[3] P.J. Giarratano, V.D. Arp, and R.V. Smith, "Forced Convection Heat Transfer to S'dpercritical Helium," Cryogenics, vol. 11, pp. 385-393, 1971.

[4] B.A. Hands, HEPROP-a Computer Programme for the Thermodynamic and Thermophysical Properties of Helium-third ed. Dept. report 1289/79, Cryogenics Laboratory, Dept. of Engineering Science, University of Oxford, April 1979.

[5] S.V. Patankar, Numerical Heat Transfer and Fluid Flow Hemisphere Publishing Co., New York, 1980.

[6] L.P. Petzold, "A Description of DASSL: A Differential/Algebraic System Solver," SAND82-8637, Sandia National Laboratories, Livermore, CA, Sept. 1982.

[7] J.R. Miller, L. Dresner, J.W. Lue, S.S. Shen, and H.T. Yeh, "Pressure Rise During the Quench of a Superconducting Magnet Using Internally Cooled Conductors," Proc. of the 8th International Cryogenic Engineering Conference Genoa, Italy, IPC Science and Technology Press, pp. 321-329, 1980.

[8] J.W. Lue, J.R. Miller, L. Dresner, and S.S. Shen, "Sin. 'lation of the Quenching of an Internally Cooled Supercunducting Magnet," Proc. 9th International Cryogenic Engineering Conference Kobe, Japan, Butterworths, pp. 814-818, 1982.

[9] R.L. Wong, Program CICC, Flow and Heat Transfer in Cabte In Conduit Conductors -- Equations and 
Verification. IJCID 21733, Lawrence Livermore National Laboratory,May 22, 1989.

[10] R.L. Wong Program CICC. Flow and Heal Transfer in Cable In Conduit Conductors - User's Manual. Lawrence Livermore National Laboratory UCID report in publication, 1989.

\section{Nomenclature}

$A_{c}=$ Cross-sectional area of He ftow channel, $\mathrm{m}^{2}$

$A_{c c}=$ Cross-sectional area of conductor, $\mathrm{m}^{2}$

$\left(A_{c e}\right)_{n}=$ Cross-sectional area of $n$th epoxy layer, $m^{2}$

$\mathrm{A}_{\mathrm{cW}} \quad=$ Cross-sectional area of conduit wall, $\mathrm{m}^{2}$

$A_{t c}=$ Convection heat-transfer perimeter for conductor, $m$

$\left(A_{t e}\right)_{n}=(n-1)$ th to nth epoxy-layer-interface perimeter, m

$A_{\text {tw }}=$ Convection heat-transfer perimeter for conduit wall, $\mathrm{m}$

$C_{c}=$ Conductor heat capacity, $\mathrm{J} / \mathrm{kg} \cdot \mathrm{K}$

$\mathrm{C}_{\mathrm{Cu}}=$ Conductor copper heat capacity, $\mathrm{J} / \mathrm{kg} \cdot \mathrm{K}$

$\mathrm{C}_{\mathrm{e}}=$ Epoxy heat capacity, $\mathrm{J} / \mathrm{kg} \cdot \mathrm{K}$

$\mathrm{C}_{\mathrm{p}} \quad=$ He constant pressure heat capacity, $\mathrm{J} / \mathrm{kg} \cdot \mathrm{K}$

$c_{s c}=$ Conductor superconductor heat capacity, $\mathrm{J} / \mathrm{kg} \cdot \mathrm{K}$

$\mathrm{C}_{\mathrm{w}}=$ Conduit wall heat capacity, $\mathrm{J} / \mathrm{kg} \cdot \mathrm{K}$

$d_{h}=$ Hydraulic diameter of He flow channel for friction, $m$. (Not used for heat-transfer perimeter.)

e $\quad=$ He internal energy, $\mathrm{J} / \mathrm{kg}$

f $\quad=$ Darcy friction factor based on $d_{h}$

$\mathrm{f}_{\mathrm{Cu}}=$ Volume fraction of copper in conducior

$\mathrm{h} \quad=$ He enthalpy, $J / \mathrm{kg}$ $h_{c}=$ He convection heat-transfer coefficient, $w / m^{2} \cdot K$

$k=$ He thermal conductivity, $w / m \cdot K$

$\mathrm{k}_{\mathrm{Cu}} \quad=$ Conductor copper thermal conductivity, $\mathrm{W} / \mathrm{m} \cdot \mathrm{K}$

$\mathrm{k}_{\mathrm{e}} \quad=$ Epoxy thermal conductivity, $\mathrm{W} / \mathrm{m} \cdot \mathrm{K}$

$k_{w}=$ Conduit wall thermal conductivity, $w / m \cdot K$

$\mathrm{L} \quad \mathrm{z} \mathrm{x}$ at conductor outlet end, $\mathrm{m}$

$\mathrm{P} \quad=$ He pressure, $\mathrm{Pa}$

$\mathrm{Q}_{\text {gen }}=$ Conductor heat generation, $\mathrm{W} / \mathrm{m}^{3}$ of conductor

$\mathrm{R}_{\mathrm{c}} \quad=$ Heat-transfer resistance between He fiow and conductor, $m^{2} \cdot K / W$

$\left(R_{e}\right)_{n}=$ Heat-conduction resistance between $(n-1)$ th and $n$th epoxy layer, $m^{2} \cdot k / W$

$R_{w} \quad=$ Heat-transier resistance between. He flow and conduit wall, $\mathrm{m}^{2} \cdot \mathrm{K} / \mathrm{W}$

$\mathrm{P} \quad=$ He density, $\mathrm{kg} / \mathrm{m}^{3}$

$\mathrm{P}_{\mathrm{c}} \quad=$ Conductor density, $\mathrm{kg} / \mathrm{m}^{3}$

$\mathrm{D}_{\mathrm{Cu}}=$ Conductor copper density, $\mathrm{kg} / \mathrm{m}^{3}$

$\mathrm{Pe} \quad=$ Epoxy density, $\mathrm{kg} / \mathrm{m}^{3}$

$\rho_{\mathrm{sc}} \quad=$ Conductor superconductor density, $\mathrm{kg} / \mathrm{m}^{3}$

$\rho_{\mathrm{w}} \quad=$ Conduit wall density, $\mathrm{kg} / \mathrm{m}^{3}$

$\mathrm{t} \quad=$ Tine, $\mathrm{s}$

$T=$ He temperature, $\mathrm{K}$

$\mathrm{T}_{\mathrm{c}} \quad=$ Conductor temperature, $\mathrm{K}$

$\left(\mathrm{T}_{\mathrm{e}}\right)_{\mathrm{n}} \quad$ = nth epoxy layer temperature, $\mathrm{K}$

$\left(\mathrm{T}_{\mathrm{e}}\right)_{\mathrm{O}}=$ Epoxy outer surface temperature, $\mathrm{K}$

$\mathrm{T}_{\mathrm{w}} \quad=$ Conduit wall temperature, $\mathrm{K}$

$u=$ He velocity, $\mathrm{m} / \mathrm{s}$

$x \quad=$ Conductor length from inlet end, $m$ 